\section{OPEN}

SUBJECT AREAS:

BIOANALYTICAL

CHEMISTRY

SENSORS

Received

19 December 2013

Accepted

25 February 2014

Published

12 March 2014

Correspondence and requests for materials should be addressed to H.X.J. (hxju@nju.edu.

\footnotetext{
* These authors contributed equally to this work.
}

\title{
Ratiometric electrochemical proximity assay for sensitive one-step protein detection
}

\author{
Kewei $\operatorname{Ren}^{1 *}$, Jie $\mathrm{Wu}^{1 *}$, Feng Yan ${ }^{2} \&$ Huangxian Ju'
}

\begin{abstract}
'State Key Laboratory of Analytical Chemistry for Life Science, Department of Chemistry, Nanjing University, Nanjing 210093 , P.R. China, ${ }^{2}$ Jiangsu Institute of Cancer Prevention and Cure, Nanjing 210009 , P.R. China.
\end{abstract}

This work proposes the concept of ratiometric electrochemical proximity assay (REPA), which can be used for one-step, highly sensitive and selective detection of protein. The assay strategy was achieved on a sensing interface that was formed by hybridization of methylene blue (MB)-labeled antibody-DNA probe (MB-DNA1-Ab1) with ferrocene ( $\mathrm{Fc}$ )-labeled DNA capture probe $(\mathrm{Fc}-\mathrm{P})$ modified gold electrode. On the interface the target protein could trigger the formation of immunocomplex between MB-DNA1-Ab1 and detection antibody-DNA probe (Ab2-DNA2) and subsequently the proximity hybridization of DNA1-DNA2, which led to the departure of MB-DNA1-Ab1 from the interface. The remained Fc-P could form a hairpin structure to take $\mathrm{Fc}$ group to electrode surface. Therefore, the recognition of target protein to $\mathrm{Ab} 1$ and Ab2 resulted in both the "signal-off" of MB and the "signal-on" of Fc for dual-signal electrochemical ratiometric readout. The proposed REPA could be carried out in one-step with 40-min duration and showed a wide detection range from 0.05 to $100 \mathrm{ng} / \mathrm{mL}$ with $\mathrm{pg} / \mathrm{mL}$ limit of detection, displaying great potential for convenient point-of-care testing and commercial application.

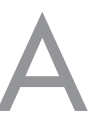

$\mathrm{s}$ the levels of tumor biomarkers in serum/tissue are positively correlated with the stages of tumors, accurate tumor marker detection with a simple operation is very important in early cancer screening and evaluation ${ }^{1-4}$. The development of rapid, easy-to-use, low-cost point-of-care methods for the quantitative detection of tumor markers has attracted the great efforts of the scientific organizations ${ }^{5}$. Immunoassay is one of the dominant methods for detection of tumor protein marker due to its highly specific molecular recognition between antibody and antigen. However, conventional immunoassays such as enzyme-linked immunosorbent assay (ELISA) are difficult to realize point-of-care detection ${ }^{6}$. Currently, DNA-assisted protein detections have been developed for clinical diagnosis, food and environmental analyses ${ }^{7-11}$. In these techniques, powerful nucleic acid detection is used for protein analysis by equipping protein-binding reagent, typically antibody, with DNA strand to improve the analytical performance ${ }^{12}$. Immuno-PCR is one of the most successful examples ${ }^{13}$. Similar to ELISA, it is performed on a capture antibody immobilized solid-support. After a sandwich immunoreaction, the DNA sequence labeled on the immunocomplex is exponentially amplified by PCR to sensitively signal the immune-recognition event ${ }^{14-18}$. The sensitivity of immuno-PCR can be further improved by introducing a biobarcode probe ${ }^{19}$. Other isothermal DNA amplification strategies, such as rolling circle amplification and hybridization chain reaction, have also been employed for sensitive protein detection by in situ DNA amplification ${ }^{20-25}$. Unfortunately, these assays require multi-step procedures, which limits their application in accurate and quick point-of-care testing.

The proximity ligation assay (PLA) is a newly developed homogenous DNA-assisted immunoassay. Its detection mechanism relies on the simultaneous recognition of target protein by a pair of PLA probes and the replication of the ligation product with PCR $^{26-29}$. Compared with ELISA and immuno-PCR, PLA is much simpler and faster ${ }^{30-33}$. This work combined the ratiometric detection technology with the proximity ligation to propose a novel concept, named as ratiometric electrochemical proximity assay (REPA), for one-step sensitive detection of protein.

Electrochemical devices are attractive in point-of-care testing because of their high sensitivity with relatively simple and low-cost measurement systems ${ }^{2,34}$. By designing artful target-induced DNA assemblies on the electrode surface, various electrochemical bioanalysis strategies have been proposed for the detection of DNA and proteins $^{35-38}$. For example, by combining the proximity ligation with DNA-based electrochemical detection, different electrochemical proximity assays have been presented ${ }^{39-41}$. In these assays, the target protein can be 
measured directly by using the proximity effect to regulate the electrochemical active label on electrode surface. However, these methods generally show relatively narrow detection range. The introduction of ratiometric detection technology in this work greatly extended the detectable concentration range.

Ratiometric detection has extensively been developed in fluorescence and electrochemiluminescence analysis of biomolecules ${ }^{42-44}$. Recently this technology has been employed in voltammetric detection of metal ion using a two-channel biosensor array ${ }^{45}$. Similar to a recently reported sensing interface, which was structured using a methylene blue (MB)-labeled DNA modified gold electrode to hybridize ferrocene $(\mathrm{Fc})$-labeled aptamer probe for detection of ATP with the sum of peak current changes ${ }^{46}$, this work immobilized Fc-labeled DNA probe (Fc-P) and MB-labeled antibody-DNA (MBDNA1-Ab1) at the same electrode. Upon the proximity hybridization with another antibody-DNA triggered by target protein, MB released from the electrode surface and Fc approached to the electrode due to the formation of a hairpin structure, which led to "signal-off" and "signal-on" elements for dual-signal electrochemical ratiometric readout (Figure 1). The dual-peak current ratiometry provided precise and sensitive measurement. The excellent performance of the proposed REPA for detection of prostate specific antigen (PSA) showed potential application of this strategy in convenient point-of-care testing.

\section{Results}

Characterization of REPA. Electrochemical impedance spectroscopic (EIS) measurements were performed in $0.1 \mathrm{M} \mathrm{KCl}$ containing $5 \mathrm{mM}$ $\mathrm{K}_{3} \mathrm{Fe}(\mathrm{CN})_{6}$ and $\mathrm{K}_{4} \mathrm{Fe}(\mathrm{CN})_{6}$ to provide information on the surface conductivity of the REPA sensor (Figure $2 \mathrm{~A})^{47}$. Compared with the bare Au electrode (curve a), the Fc-P modified Au electrode showed a much larger $R_{\text {et }}$ (curve b) because the self-assembly layer of negatively charged Fc-P could repel the $\left[\mathrm{Fe}(\mathrm{CN})_{6}\right]^{3-/ 4-}$ to the electrode surface. Subsequent surface blocking with mercaptohexanol $(\mathrm{MCH})$ led to an increase of $R_{\text {et }}$ (curve c). After MB-DNA1-Abl was captured on the $\mathrm{Au}$ electrode through its hybridization with $\mathrm{Fc}-\mathrm{P}$, the $R_{\mathrm{et}}$ further increased due to the insulativity of protein (curve d). Similarly, target protein, PSA, could also resist the electron transfer, resulting in the increasing impedance (curve e), which reflected the successful recognition between MB-DNA1-Ab1 and PSA. However, in the presence of both target PSA and detection antibody-DNA probe
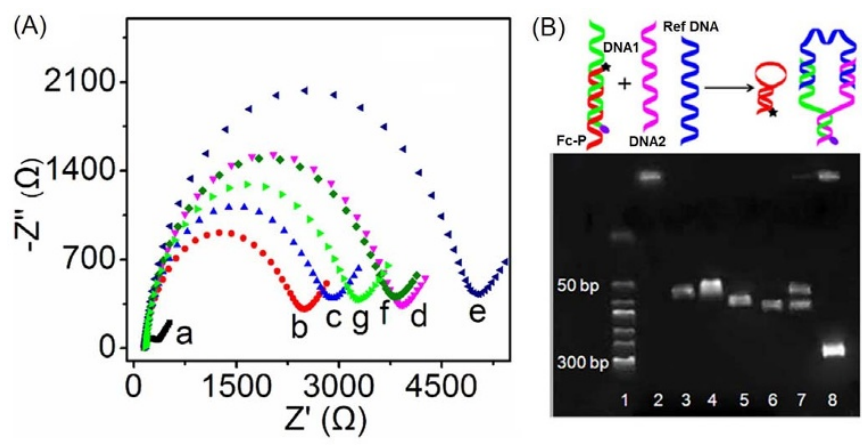

Figure $2 \mid$ Characterization of REPA. (A) EIS of bare Au electrode (a), Fc$\mathrm{P}$ modified Au electrode (b), (b) blocked with MCH (c), REPA sensor $(d),(d)$ reacted with $10 \mathrm{ng} / \mathrm{mL}$ PSA $(e),(d)$ reacted with $50 \mathrm{nM}$ Ab2-DNA2 (f), and (d) reacted with the mixture of $10 \mathrm{ng} / \mathrm{mL}$ PSA and $50 \mathrm{nM}$ Ab2-DNA2 (g). (B) PAGE analysis of DNA-based REPA. Lanes 1-8 represent the DNA ladder marker, Fc-P, DNA1, DNA2, Ref DNA, the mixture of Fc-P and DNA1, the mixture of Fc-P, DNA1 and DNA2, and the mixture of Fc-P, DNA1, DNA2 and Ref DNA at $10 \mu \mathrm{M}$, respectively. DNA2 (L13) was used in PAGE.

(Ab2-DNA2), the immunoreaction of Ab1-target-Ab2 triggered the proximity hybridization of DNA1-DNA2 and the formation of a cooperative complex between MB-DNA1-Ab1 and Ab2-DNA2, leading to the dissociation of MB-DNA1-Ab1 from the sensor surface, and thus the decrease of the corresponding $R_{\text {et }}$ (curve g). In contrast, no change of $R_{\mathrm{et}}$ was observed after the REPA sensor was incubated only with Ab2-DNA2 (curve f). Overall, all these experimental results demonstrated the successful fabrication of the sensor and the REPA of PSA according to Figure 1.

Furthermore, this work utilized a Ref DNA to mimic the Ab1target-Ab2 complex in REPA for polyacrylamide gel electrophoresis (PAGE) analysis (Figure 2B). The Ref DNA could bring the DNA1 and DNA2 in proximity to form a cooperative complex. Fc-P, DNA1, DNA2 and Ref DNA exhibited individual clear band, respectively (lanes 2-5). As Fc-P had 12 bases complementary to DNA1, the mixture of Fc-P and DNA1 produced dsDNA, which moved slower than both Fc-P and DNA1 (lane 6). In the absence of Ref DNA, the mixture of Fc-P, DNA1 and DNA2 displayed two bands located in

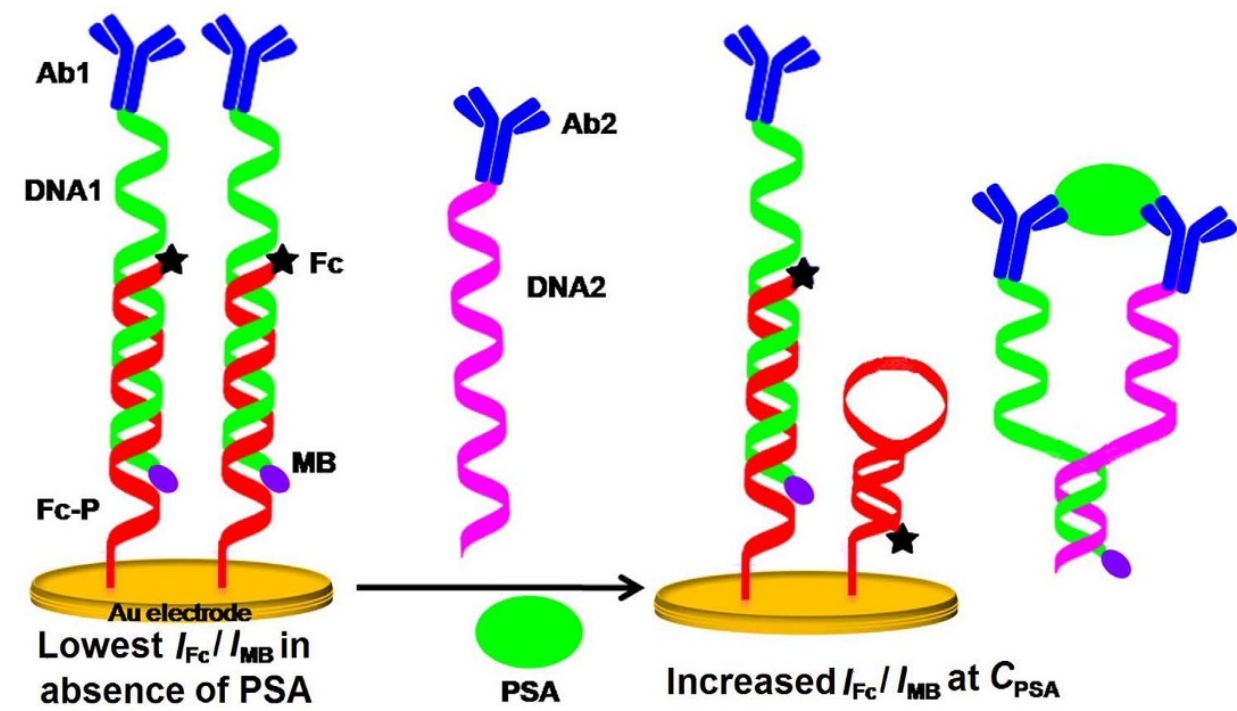

Figure 1 Schematic illustration of REPA. The assay uses Fc-P modified gold electrode to hybridize MB-DNA1-Ab1 for preparation of sensing interface. The target protein triggers the immunoreaction of Ab1-target-Ab2 and subsequently the proximity hybridization of DNA1 and DNA2, which leads to the departure of MB-DNA1-Ab1 from the sensing surface and the formation of a hairpin structure of Fc-P to produce "signal-off" of MB and "signalon" of Fc for dual-signal electrochemical ratiometric readout. 


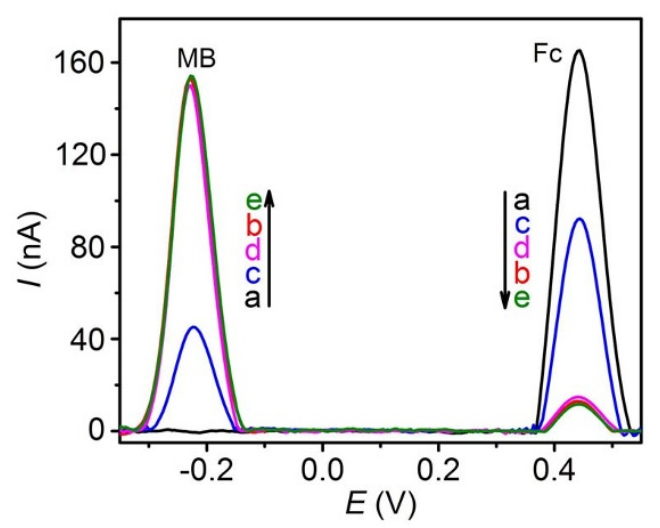

Figure 3 Feasibility of REPA. ACV responses of Fc-P modified Au electrode (a), REPA sensor (b), (b) incubated with Ab2-DNA2 in presence (c) and absence (d) of $10 \mathrm{ng} / \mathrm{mL}$ PSA, and (b) incubated with $10 \mathrm{ng} / \mathrm{mL}$ PSA without Ab2-DNA2 (e).

the same position as the dsDNA and DNA2 (lane 7), indicating no hybridization occurred between dsDNA and DNA2. Upon the addition of Ref DNA to the mixture of Fc-P, DNA1 and DNA2, a new band with a slow migration speed appeared, along with the appearance of Fc-P band (lane 8). This result should be contributed to the formation of proximate complex product of DNA1-Ref DNA-DNA2 and the displacement of Fc-P from dsDNA, verifying the proximity hybridization induced DNA displacement strategy.

Feasibility of REPA. The feasibility of REPA was investigated by measuring alternating current voltammetric (ACV) responses of different modified electrodes (Figure 3 and Supplemental Data Figure s1). The Au electrode modified with hairpin structured Fc-P showed only large oxidation peak of Fc at about $+0.44 \mathrm{~V}$ (curve a). After hybridization with MB-DNA1-Ab1, a sharp MB peak appeared at $-0.22 \mathrm{~V}$, accompanied by a substantial decrease of the Fc response (curve b), suggesting the successful construction of the REPA sensor according to Figure 1. Here, although $\mathrm{MB}$ and Fc underwent a 2electron and 1-electron transfer upon the electrochemical oxidation, respectively, they showed similar change of absolute current, indicating their different electron-transfer rate constants due to the different distances from the electrode ${ }^{48}$. When the REPA sensor was incubated both with PSA and Ab2-DNA2, the simultaneous recognition of the target protein by the two Ab-DNA probes along with the hybridization of complementary bases in DNA1 and DNA2 led to the formation of proximate cooperative complex between MBDNA1-Ab1 and Ab2-DNA2, resulting in the dissociation of MBDNA1-Ab1 from the electrode, meanwhile, the complementary base pairs in left Fc-P formed a hairpin structure on the electrode surface. As a result, the Fc group approached electrode surface to increase its peak current, and the peak current corresponding to the oxidation of MB significantly decreased (curve c). In contrast, in the absence of target protein, no current change was observed for both $\mathrm{MB}$ and Fc (curve d), indicating that the hybridization between DNA1 and DNA2 did not happen without the help of proximity effect. Therefore, the proximity ligation induced DNA displacement and the following peak current changes depended on the presence of target protein. Interestingly, in the absence of DNA2, although the target protein could be recognized by MB-DNA1-Ab1 to be bound on electrode surface, the ACV signal changes of both MB and Fc were also very slight (curve e), indicating the bound protein did not affect the probe dynamic position on surface. This could be attributed to the controllable surface structure of the sensor, which led to the stable distance between the electrode and electroactive groups, thus their electron-transfer constants did not obviously change.

Optimization of detection conditions. The detection mechanism of REPA relied on simultaneous recognition of target protein by a pair of antibody-DNA affinity probes which brought DNA1 and DNA2 in proximity to process the DNA displacement. Thus, the number of complementary bases between DNA1 and DNA2 should be firstly optimized. This was because at low number of complementary bases DNA2 could not displace the DNA1 from the sensor surface even with the help of proximate effect, while at high number of complementary bases DNA2 could hybridize with DNA1 without the help of proximate effect, producing a large background. Figure 4A shows the signals and backgrounds of the REPA when using Ref DNA and DNA2 with 11,13 and 15 complementary bases (L11, L13, and L15) to DNA1 for proximity hybridization. In the presence of $10 \mathrm{nM}$ Ref DNA, the ratiometric peak current $\left(I_{\mathrm{Fc}} / I_{\mathrm{MB}}\right)$ increased with the increasing number of complementary bases from 11 to 15 . However, the large number of complementary bases also caused a larger background. Thus, according to the maximum signal-to-background ratio, the DNA2 (L13) was chosen for the subsequent experiments.

The incubation time was another important parameter affecting the analytical performance of REPA. At room temperature, the value of $I_{\mathrm{Fc}} / I_{\mathrm{MB}}$ greatly increased with the increasing incubation time till $40 \mathrm{~min}$, while the background was little changed (Figure 4B). To obtain high sensitivity, the optimum incubation time should be $40 \mathrm{~min}$.

The density of immobilized Fc-P onto the gold electrode could affect the analytical performance of the sensor. At an assembly time of $2 \mathrm{~h}$ at room temperature, the maximum value of $I_{\mathrm{Fc}} / I_{\mathrm{MB}}$ occurred at the Fc-P concentration of $0.5 \mu \mathrm{M}$ (Figure 4C). Higher density when higher Fc-P concentration was used would induce steric hindrances, which decreased the ability of Fc-P to form the hairpin structure on the electrode surface, while lower density would affect the detection efficiency of the sensor to target protein. Hence, the sensor was prepared with $6 \mu \mathrm{L}$ of $0.5 \mu \mathrm{M}$ Fc-P.

Assay performance. The analytical performance of REPA was characterized under optimal experimental conditions. As shown in Figure 5A and Supplemental Data Figure s2, with the increasing PSA concentration, the $\mathrm{MB}$ oxidation peak decreased and the FC
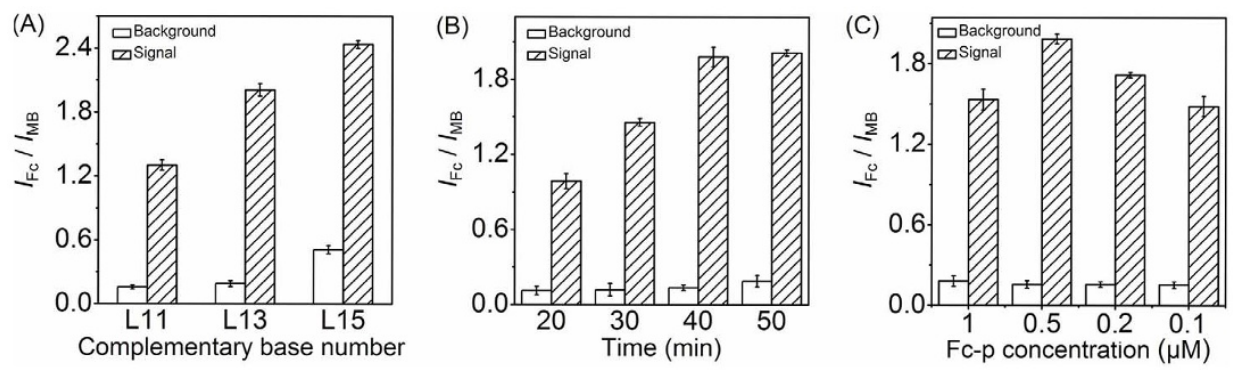

Figure $4 \mid$ Optimization of detection conditions. Effects of (A) complementary base number between DNA1 and DNA2, (B) incubation time and (C) Fc$\mathrm{P}$ concentration on $I_{\mathrm{Fc}} / I_{\mathrm{MB}}$. Error bars represent standard deviations of three parallel experiments. 

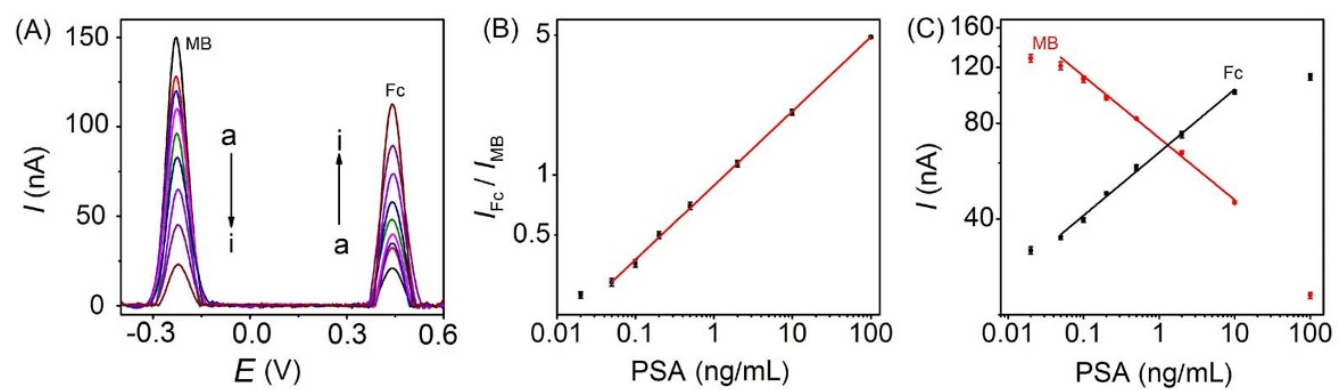

Figure $5 \mid$ Sensitive detection of PSA. (A) ACV responses of REPA sensor to 0, 0.02, 0.05, 0.1, 0.2, 0.5, 2, 10, and 100 (from a to i), (B) logarithmic dependence of $I_{\mathrm{FC}} / I_{\mathrm{MB}}$ on PSA concentration, and (C) logarithmic dependence of MB (a) or Fc (b) peak current on PSA concentration. Error bars represent standard deviations of three parallel experiments.

oxidation peak increased correspondingly. The logarithmic value of $I_{\mathrm{Fc}} / I_{\mathrm{MB}}$ linearly depended on the logarithm of PSA concentration in the range of 0.05 to $100 \mathrm{ng} / \mathrm{mL}$ with a correlation coefficient of 0.9999 (Figure $5 \mathrm{~B}$ ). The linear regression equation was $\log \left(I_{\mathrm{Fc}} / I_{\mathrm{MB}}\right)=0.37$ $\log [\mathrm{C}]-0.053$. The detection limit corresponding to a signal-to-noise ratio of 3 was $16 \mathrm{pg} / \mathrm{mL}$. It was worthy to note that the electrochemical ratiometry displayed a more sensitive and effective detection than that using single redox label. Figure $5 \mathrm{C}$ shows the calibration plots of the proximity assay using individual $\mathrm{Fc}$ or MB signal for PSA detection. Both of them exhibit good linear logarithmic relationship between the oxidation peak current and PSA concentration in the range of 0.05 to $10 \mathrm{ng} / \mathrm{mL}$, along with detection limits of 43 and $48 \mathrm{pg} / \mathrm{mL}$, respectively. Obviously dual-signal ratiometric readout extends the linear range for 1 order of magnitude, which is beneficial to real clinical application. The detection limit of the proposed REPA was also lower than other electrochemical immunoassays using complex amplification strategies ${ }^{49,50}$.

The selectivity of the REPA was evaluated by comparing the $I_{\mathrm{Fc}}$ l $I_{\mathrm{MB}}$ values toward the solutions containing either PSA or other antigen only, for example carcinoembryonic antigen (CEA), and the mixture of PSA and CEA (Figure 6). As expected, the REPA showed obvious responses to the solutions containing target PSA, while negligible response was observed in the CEA solution, indicating few non-specific binding was observed. Overall, the high sensitivity, wide detection range, easy operation and good selectivity of the REPA indicated its great potential in point-of-care testing.

Real sample analysis. To evaluate the analytical reliability and application potential of the proposed method, REPA was used to detect PSA in clinical serum samples (Supplemental Data Figure s3) and the assay results were compared with the reference values from the commercial electrochemiluminescent testing. The results

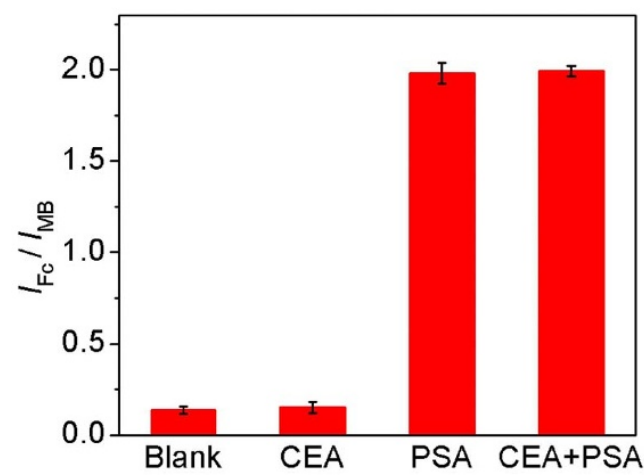

Figure 6 Selectivity of REPA. $I_{\mathrm{Fc}} / I_{\mathrm{MB}}$ on REPA sensor incubated with blank control, $10 \mathrm{ng} / \mathrm{mL}$ CEA, $10 \mathrm{ng} / \mathrm{mL}$ PSA, and the mixture of $10 \mathrm{ng} /$ $\mathrm{mL} C E A$ and PSA. Error bars represent standard deviations of three parallel experiments. were shown in Table 1, an acceptable agreement with relative errors less than $10.3 \%$ indicated good accuracy of the proposed method for the detection of clinical samples.

\section{Discussion}

This work has proposed a concept of ratiometric electrochemical proximity assay for one-step, highly sensitive and selective detection of protein. The sensing interface can be structured by self-assembling a Fc-labeled DNA probe on gold electrode and then hybridizing with a MB-labeled DNA1-Ab1 affinity probe. The simultaneous recognition of the target protein by DNA1-Ab1 and DNA2-Ab2 as detection probe triggers the hybridization of proximity complementary bases in DNA1 and DNA2 to form a proximate cooperative complex, which leads to the dissociation of MB-DNA1-Ab1 from the electrode and the approach of $\mathrm{Fc}$ group to electrode surface by forming a hairpin structure of Fc-labeled DNA probe. As a result, the oxidation peak current ratio of Fc to MB significantly increases. Using PSA as a protein model, the electrochemical ratiometric readout showed wide detection range, high sensitivity, low detection limit, good selectivity and acceptable accuracy. The REPA is simple, convenient and fast, and possesses favorable expansibility for detection of other proteins, showing great potential for point-of-care testing and commercial application.

\section{Methods}

Reagents and materials. Sulfosuccinimidyl-4-(N-maleimidomethyl)cyclohexane-1carboxylate (SMCC) was supplied by Heowns Biochem LLC (Tianjin, China). PSA and mouse monoclonal anti-PSA antibodies (clone no. P27B1 as Ab1 and P27A10 as Ab2) were purchased from Shuangliu Zhenglong Biochem. Lab (Chengdu, China). The clinical serum samples were from Jiangsu Institute of Cancer Prevention and Cure. Ultrapure water obtained from a Millipore water purification system ( $\geq 18 \mathrm{M} \Omega$, Milli-Q, Millipore) was used in all assays. $6 \times$ DNA loading buffer was bought from Solarbio Co. Ltd (Beijing, China). Low molecular DNA ladder was purchased from Fermentas. Dithiothreitol (DTT) and oligonucleotides were obtained from Sangon Biotechnology Inc. (Shanghai, China), and their sequences were listed as following:

Fc-P: 5' -Fc-CGCGTTAACATACAATAGATCGCG- $\left(\mathrm{CH}_{2}\right)_{6}-\mathrm{SH}-3^{\prime}$

MB-labeled DNA1: $5^{\prime}$-MB-

GCGGATCTATTGTATCACATATTTTTTTTTTTTTTTTTT

CACCGTATGCTACTGTAGAT-SH-3'

Thiolated DNA2 (L13): $5^{\prime}-\mathrm{SH}-$

TAGGAAAAGGAGGAGGGTGGTTTTTTTTTTTTTTT

TTTTTTTAGATACAATAGATC-3'

DNA2 (L11): $5^{\prime}$ -

TAGGAAAAGGAGGAGGGTGGTTTTTTTTTTTTTTTTTTTTTTACT

TACAATAGATC-3'

DNA2 (L13): $5^{\prime}-$

TAGGAAAAGGAGGAGGGTGGTTTTTTTTTTTTTTTTTTTTTTAGA

TACAATAGATC-3'

DNA2 (L15): 5' -

TAGGAAAAGGAGGAGGGTGGTTTTTTTTTTTTTTTTTTTTAGTGA

TACAATAGATC-3'

Ref DNA: $5^{\prime}$ -

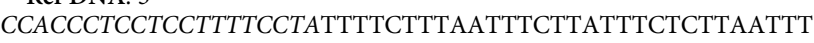

TAATTTGTTTATCTACAGTAGCATACGGTG-3' 
Table 1 Assay results of clinical serum samples using the proposed and reference methods

\begin{tabular}{lccc} 
Sample No. & Proposed $\operatorname{method}(\mathrm{ng} / \mathrm{mL})$ & Reference method ${ }^{[a]}(\mathrm{ng} / \mathrm{mL})$ & Relative error $(\%)$ \\
\hline 1 & 10.95 & 11.61 & -5.68 \\
2 & 6.83 & 6.19 & 10.34 \\
3 & 0.359 & 0.332 & 8.13 \\
4 & 8.39 & 8.01 & 4.74 \\
\hline
\end{tabular}

[a]The reference levels were detected with an automated electrochemiluminescent analyzer (Elecsys 2010, Roche).

The bold and italics parts represented the binding regions of DNA1 to Fc-P (or DNA2), and Ref DNA to DNA1 and DNA2, respectively.

Apparatus. The electrochemical measurements were performed on a $\mathrm{CHI} 630 \mathrm{D}$ electrochemical workstation (CH Instruments Inc., U.S.A.) at room temperature with a conventional three-electrode system composed of a platinum wire as counter, $\mathrm{Ag} /$ $\mathrm{AgCl}$ as reference and the $\mathrm{Au}$ electrode as working electrodes. Electrochemical impedance spectroscopic measurements were carried out on a PGSTAT30/FRA2 system (Autolab, the Netherlands) in $0.1 \mathrm{M} \mathrm{KCl}$ containing $5 \mathrm{mM} \mathrm{K}_{3} \mathrm{Fe}(\mathrm{CN})_{6} /$ $\mathrm{K}_{4} \mathrm{Fe}(\mathrm{CN})_{6}$. PAGE analysis was performed on an Electrophoresis Analyser (Liuyi Instrument Company, China) and imaged on the Bio-rad ChemDoc XRS (Bio-Rad, USA).

Preparation of Ab-DNA probes. The Ab-DNA probes were synthesized by chemically cross-linking the respective antibody to thiolated ssDNA with and without MB label ${ }^{51}$. The antibody $(2 \mathrm{mg} / \mathrm{mL})$ was firstly reacted with a 20 -fold molar excess of SMCC in PBS (55 mM phosphate, $\mathrm{pH} 7.4,150 \mathrm{mM} \mathrm{NaCl}, 20 \mathrm{mM}$ EDTA) for $2 \mathrm{~h}$ at room temperature. In parallel, $3 \mu \mathrm{L}$ of $100 \mu \mathrm{M}$ thiolated ssDNA was reduced with $4 \mu \mathrm{L}$ of $100 \mathrm{mM}$ DTT in PBS for $1 \mathrm{~h}$ at $37^{\circ} \mathrm{C}$. Both the products were purified by ultrafiltration (10, $000 \mathrm{MW}$ cut-off membrane, Millipore) for eight times and the buffer was changed to PBE ( $55 \mathrm{mM}$ phosphate, $\mathrm{pH} 7.4,150 \mathrm{mM} \mathrm{NaCl}, 5 \mathrm{mM}$ EDTA). After the products were mixed to incubate over night at $4{ }^{\circ} \mathrm{C}$ and the unreacted DNA was removed by ultrafiltration (100, $000 \mathrm{MW}$ cut-off membrane, Millipore) for eight times, the Ab-DNA probe was obtained.

Fabrication of REPA sensor. Gold electrode $(\sim 2 \mathrm{~mm}$ diameter, $\mathrm{CH}$ Instrument Inc.) was polished carefully to a mirror surface with aqueous slurry of $0.3 \mu \mathrm{m}$ diameter alumina particles and then successively washed in an ultrasonic cleaner with water and ethanol. The electrode was then immersed into fresh piranha solution $\left(\mathrm{H}_{2} \mathrm{SO}_{4} / \mathrm{H}_{2} \mathrm{O}_{2}, 3: 1\right)$ for $10 \mathrm{~min}$, rinsed with water, and dried under a stream of nitrogen gas. Finally, the gold electrode was electrochemically polished by scanning the potential from -0.2 to $+1.6 \mathrm{~V}$ in $0.5 \mathrm{M} \mathrm{H}_{2} \mathrm{SO}_{4}$ at scan rate of $0.1 \mathrm{~V} / \mathrm{s}$ for 40 cycles. The cleaned gold electrode was thoroughly washed with water and dried under flowing nitrogen.

$6 \mu \mathrm{L}$ of $0.5 \mu \mathrm{M} \mathrm{Fc}-\mathrm{P}$ was dropped on the electrode to incubate at room temperature for $2 \mathrm{~h}$. After rinsed with $10 \mathrm{mM} \mathrm{pH} 7.4$ Tris $-\mathrm{HCl}$ buffer and dried with nitrogen, $6 \mu \mathrm{L}$ of $1 \mathrm{mM} \mathrm{MCH}$ was dropped on the electrode for $1 \mathrm{~h}$ to block the unmodified sites. After washing with Tris- $\mathrm{HCl}$ buffer and drying with nitrogen, $6 \mu \mathrm{L}$ of $1 \mu \mathrm{M}$ MB-DNA1-Abl containing $0.5 \%$ BSA ( $\mathrm{w} / \mathrm{v}$ ) was coated on the electrode for overnight incubation. After another washing step, the REPA sensor was obtained and stored at $4^{\circ} \mathrm{C}$ before use.

Measurement procedure. Prior to measurement, Tris- $\mathrm{HCl}$ buffer ( $\mathrm{pH}$ 7.4, $0.5 \mathrm{M}$ $\mathrm{NaCl}$ ) was supplemented with $0.5 \% \mathrm{BSA}(\mathrm{w} / \mathrm{v}), 50 \mathrm{nM} \mathrm{Ab2-DNA2}$, and various concentrations of PSA or serum samples. $6 \mu \mathrm{L}$ of above solution was dropped on the sensor surface for 40-min incubation, followed by washing with Tris-HCl buffer $(\mathrm{pH}$ 7.4) $)^{52}$. Then, the sensor was immersed in $10 \mathrm{mM} \mathrm{pH} \mathrm{7.4} \mathrm{PBS} \mathrm{for} \mathrm{ACV} \mathrm{detection} \mathrm{from}$ -0.4 to $+0.6 \mathrm{~V}$ with a step potential of $4 \mathrm{mV}$, a frequency of $25 \mathrm{~Hz}$ and an amplitude of $25 \mathrm{mV}$.

PAGE analysis. The $12 \%$ native PAGE was prepared using $1 \times$ Tris-Borate-EDTA (TBE) buffer. The loading sample was mixed with $7 \mu \mathrm{L}$ DNA sample, $1.5 \mu \mathrm{L} 6 \times$ loading buffer and $1.5 \mu \mathrm{L}$ UltraPower dye, and kept for 3 min so that the dye could integrate with DNA completely. Then the loading sample was applied onto the lane. The gel was run at $90 \mathrm{~V}$ for $90 \mathrm{~min}$ in $1 \times \mathrm{TBE}$ buffer, and scanned using a Molecular Imager Gel Doc XR (BIO-RAD, USA).

1. Zong, C., Wu, J., Wang, C., Ju, H. X. \& Yan, F. Chemiluminescence imaging immunoassay of multiple tumor markers for cancer screening. Anal. Chem. 84, 2410-2415 (2012)

2. Rusling, J. F. Multiplexed electrochemical protein detection and translation to personalized cancer diagnostics. Anal. Chem. 85, 5304-5310 (2013).

3. Lin, J. H. \& Ju, H. X. Electrochemical and chemiluminescent immunosensors for tumor markers. Biosens. Bioelectron. 20, 1461-1470 (2005).

4. Wu, J., Fu, Z. F., Yan, F. \& Ju, H. X. Biomedical and clinical applications of immunoassays and immunosensors for tumor markers. TrAC, Trends Anal. Chem. 26, 679-688 (2007).
5. Urdea, M. et al. Requirements for high impact diagnostics in the developing world. Nature 444, 73-79 (2006).

6. Akter, R., Rahman, M. A. \& Rhee, C. K. Amplified electrochemical detection of a cancer biomarker by enhanced precipitation using horseradish peroxidase attached on carbon nanotubes. Anal. Chem. 84, 6407-6415 (2012).

7. Kattah, M. G., Coller, J., Cheung, R. K., Oshidary, N. \& Utz, P. J. HIT: a versatile proteomics platform for multianalyte phenotyping of cytokines, intracellular proteins and surface molecules. Nat. Med. 14, 1284-1289 (2008).

8. Tavoosidana, G. et al. Multiple recognition assay reveals prostasomes as promising plasma biomarkers for prostate cancer. Proc. Natl. Acad. Sci. U.S.A. 108, 8809-8814 (2011)

9. Cheng, S. Y. et al. Sensitive detection of small molecules by competitive immunomagnetic-proximity ligation assay. Anal. Chem. 84, 2129-2132 (2012).

10. Weibrecht, I. et al. In situ detection of individual mRNA molecules and protein complexes or post-translational modifications using padlock probes combined with the in situ proximity ligation assay. Nat. Protoc. 8, 355-372 (2013).

11. Jung, J., Lifland, A. W., Zurla, C., Alonas, E. J. \& Santangelo, P. J. Quantifying RNA-protein interactions in situ using modified-MTRIPs and proximity ligation. Nucleic Acids Res. 41, e12 (2013).

12. Nong, R. Y., Gu, J. J., Darmanis, S., KamaliMoghaddam, M. \& Landegren, U. DNA-assisted protein detection technologies. Expert Rev. Proteomics 9, 21-32 (2012).

13. Sano, T., Smith, C. L. \& Cantor, C. R. Immuno-PCR: very sensitive antigen detection by means of specific antibody-DNA conjugates. Science 258, 120-122 (1992).

14. Burbulis, I., Yamaguchi, K., Gordon, A., Carlson, R. \& Brent, R. Using proteinDNA chimeras to detect and count small numbers of molecules. Nat. Methods $\mathbf{2}$, 31-37 (2005).

15. Guo, Y. C. et al. Phage display mediated immuno-PCR. Nucleic Acids Res. 34, e62 (2006).

16. Wang, T. W., Lu, H. Y., Lou, P. J. \& Lin, F. H. Application of highly sensitive, modified glass substrate-based immuno-PCR on the early detection of nasopharyngeal carcinoma. Biomaterials 29, 4447-4454 (2008).

17. Yu, X., Burgoon, M. P., Shearer, A. J. \& Gilden, D. H. Characterization of phage peptide interaction with antibody using phage mediated immuno-PCR. J. Immunol. Methods 326, 33-40 (2007).

18. Barletta, J., Bartolome, A. \& Constantine, N. T. Immunomagnetic quantitative immuno-PCR for detection of less than one HIV-1 virion. J. Virol. Methods 157, 122-132 (2009)

19. Nam, J. M., Thaxton, C. S. \& Mirkin, C. A. Nanoparticle-based bio-bar codes for the ultrasensitive detection of proteins. Science 301, 1884-1886 (2003).

20. Schweitzer, B. et al. Immunoassays with rolling circle DNA amplification: A versatile platform for ultrasensitive antigen detection. Proc. Natl. Acad. Sci. U.S.A. 97, 10113-10119 (2000).

21. Ericsson, O. et al. A dual-tag microarray platform for high-performance nucleic acid and protein analyses. Nucleic Acids Res. 36, e45 (2008).

22. Schweitzer, B. et al. Multiplexed protein profiling on microarrays by rolling-circle amplification. Nat. Biotechnol. 20, 359-365 (2002).

23. Yan, J. et al. An on-nanoparticle rolling-circle amplification platform for ultrasensitive protein detection in biological fluids. Small 6, 2520-2525 (2010).

24. Zhang, B. et al. DNA-based hybridization chain reaction for amplified bioelectronic signal and ultrasensitive detection of proteins. Anal. Chem. 84, 5392-5399 (2012).

25. Tong, L., Wu, J., Li, J., Ju, H. X. \& Yan, F. Hybridization chain reaction engineered DNA nanopolylinker for amplified electrochemical sensing of biomarkers. Analyst 138, 4870-4876 (2013)

26. Darmanis, S. et al. Sensitive plasma protein analysis by microparticle-based proximity ligation assays. Mol. Cell. Proteomics 9, 327-335 (2010).

27. Torre, T. Z. G. et al. Sensitive detection of spores using volume-amplified magnetic nanobeads. Small 8, 2174-2177 (2012).

28. Nong, R. Y. et al. Solid-phase proximity ligation assays for individual or parallel protein analyses with readout via real-time PCR or sequencing. Nat. Protoc. 8 , 1234-1248 (2013).

29. Fredriksson, S. et al. Multiplexed protein detection by proximity ligation for cancer biomarker validation. Nat. Methods 4, 327-329 (2007).

30. Tavoosidana, G. et al. Multiple recognition assay reveals prostasomes as promising plasma biomarkers for prostate cancer. Proc. Natl. Acad. Sci. U.S.A. 108, 8809-8814 (2011). 
31. Gullberg, M. et al. Cytokine detection by antibody-based proximity ligation. Proc. Natl. Acad. Sci. U.S.A. 101, 8820-8824 (2004).

32. Weibrecht, I. et al. In situ detection of individual mRNA molecules and protein complexes or post-translational modifications using padlock probes combined with the in situ proximity ligation assay. Nat. Protoc. 8, 355-372 (2013).

33. Jung, J., Lifland, A. W., Zurla, C., Alonas, E. J. \& Santangelo, P. J. Quantifying RNA-protein interactions in situ using modified-MTRIPs and proximity ligation. Nucleic Acids Res. 41, e12 (2013).

34. Deng, W. et al. Diagnosis of schistosomiasis japonica with interfacial co-assemblybased multi-channel electrochemical immunosensor arrays. Sci. Rep. 3, 1789 (2013).

35. Fan, C. H., Plaxco, K. W. \& Heeger, A. J. Electrochemical interrogation of conformational changes as a reagentless method for the sequence-specific detection of DNA. Proc. Natl. Acad. Sci. U.S.A. 100, 9134-9137 (2003).

36. Li, D., Song, S. P. \& Fan, C. H. Target-responsive structural switching for nucleic acid-based sensors. Acc. Chem. Res. 43, 631-641 (2010).

37. Kang, D. et al. DNA biomolecular-electronic encoder and decoder devices constructed by multiplex biosensors. NPG Asia Mater. 4, 10.1038/am.2012.1 (2012).

38. Zuo, X. L. et al. A target-responsive electrochemical aptamer switch (TREAS) for reagentless detection of nanomolar ATP. J. Am. Chem. Soc. 129, 1042-1043 (2007).

39. Hu, J. M., Wang, T. Y., Kim, J., Shannon, C. \& Easle, C. J. Quantitation of femtomolar protein levels via direct deadout with the electrochemical proximity assay. J. Am. Chem. Soc. 134, 7066-7072 (2012).

40. Zhang, Y. L., Huang, Y., Jiang, J. H., Shen, G. L. \& Yu, R. Q. Electrochemical aptasensor based on proximity-dependent surface hybridization assay for singlestep, reusable, sensitive protein detection. J. Am. Chem. Soc. 129, 15448-15449 (2007).

41. Zhang, Y. L., Pang, P. F., Jiang, J. H., Shen, G. L. \& Yu, R. Q. Electrochemical aptasensor based on proximity-dependent surface hybridization assay for protein detection. Electroanalysis 21, 1327-1333 (2009).

42. Zhang, P., Beck, T. \& Tan, W. H. Design of a molecular beacon DNA probe with two fluorophores. Angew. Chem. Int. Ed. 40, 402-405 (2001).

43. Zhang, H. R., Xu, J. J. \& Chen, H. Y. Electrochemiluminescence ratiometry: a new approach to DNA biosensing. Anal. Chem. 85, 5321-5325 (2013).

44. Gong, Y. J. et al. Through bond energy transfer: a convenient and universal strategy toward efficient ratiometric fluorescent probe for bioimaging applications. Anal. Chem. 84, 10777-10784 (2012).

45. Chai, X. L. et al. A two-channel ratiometric electrochemical biosensor for in vivo monitoring of copper ions in a rat brain using gold truncated octahedral microcages. Angew. Chem. Int. Ed. 52, 1-6 (2013).

46. Wu, L., Zhang, X. H., Liu, W., Xiong, E. H. \& Chen, J. H. Sensitive electrochemical aptasensor by coupling "signal-on"and "signal-off"strategies. Anal. Chem. 85, 8397-8402 (2013).
47. Cao, Y. et al. Protein detection based on small molecule-linked DNA. Anal. Chem. 84, 4314-4320 (2012).

48. Yang, W. W. \& Lai, R. Y. A dual-signalling electrochemical DNA sensor based on target hybridization-induced change in DNA probe flexibility. Chem. Commun. 48, 8703-8705 (2012).

49. Yu, X. et al. Carbon nanotube amplification strategies for highly sensitive immunodetection of cancer biomarkers. J. Am. Chem. Soc. 128, 11199-11205 (2006).

50. Zani, A., Laschi, S., Mascini, M. \& Marrazza, G. A new electrochemical multiplexed assay for PSA cancer marker detection. Electroanalysis 23, 91-99 (2011).

51. Söderberg, O. et al. Direct observation of individual endogenous protein complexes in situ by proximity ligation. Nat. Methods 3, 995-1000 (2006).

52. Ferapontova, E. E., Olsen, E. M. \& Gothelf, K. V. An RNA aptamer-based electrochemical biosensor for detection of theophylline in serum. J. Am. Chem. Soc. 130, 4256-4258 (2008).

\section{Acknowledgments}

We gratefully acknowledge the National Basic Research Program (2010CB732400), National Natural Science Foundation of China (21075055, 21135002, 21121091 and 21105046, 21361162002), PhD Fund (20110091120012, 20130091130005), the Leading Medical Talents Program from Department of Health of Jiangsu Province, and Science Foundation of Jiangsu (BK2011552 and BL2013036).

\section{Author contributions}

K.R., J.W. and H.J. conceived and designed the experiments. K.R., J.W. and F.Y. performed the experiments. K.R., J.W. and H.J. analysed the data and wrote the paper. All authors discussed and commented on the manuscript.

\section{Additional information}

Supplementary information accompanies this paper at http://www.nature.com/ scientificreports

Competing financial interests: The authors declare no competing financial interests.

How to cite this article: Ren, K.W., Wu, J., Yan, F. \& Ju, H.X. Ratiometric electrochemical proximity assay for sensitive one-step protein detection. Sci. Rep. 4, 4360; DOI:10.1038/ srep04360 (2014).

(c) (1) (2) This work is licensed under a Creative Commons AttributionBY NC SA NonCommercial-ShareAlike 3.0 Unported license. To view a copy of this license, visit http://creativecommons.org/licenses/by-nc-sa/3.0 